\title{
1 Alkaline flocculation of Phaeodactylum tricornutum induced by brucite and \\ 2 calcite \\ 3
}

4 Dries Vandamme ${ }^{1 *}$, Philip I. Pohl ${ }^{2}$, Annelies Beuckels ${ }^{1}$, Imogen Foubert ${ }^{3,4}$, Patrick V.

5 Brady $^{2}$, John C. Hewson ${ }^{2}$, Koenraad Muylaert ${ }^{1}$

6

$7{ }^{1}$ KU Leuven Kulak, Laboratory Aquatic Biology, E. Sabbelaan 53, 8500 Kortrijk,

8 Belgium

$9 \quad{ }^{2}$ Sandia National Laboratories, Albuquerque, NM, USA.

$10{ }^{3}$ KU Leuven Kulak, Research Unit Food \& Lipids, Department of Molecular and

11 Microbial Systems Kulak, Etienne Sabbelaan 53, B-8500 Kortrijk, Belgium

$12{ }^{4}$ Leuven Food Science and Nutrition Research Centre (LFoRCe), KU Leuven

13 Kasteelpark Arenberg 20, B-3001 Heverlee, Belgium

14

15 *Corresponding Author: dries.vandamme@kuleuven-kulak.be

16 Tel: +3256246041

17 
20 Alkaline flocculation holds great potential as a low-cost harvesting method for marine

21 microalgae biomass production. Alkaline flocculation is induced by an increase in $\mathrm{pH}$

22 and is related to precipitation of calcium and magnesium salts. In this study, we used

23 the diatom Phaeodactylum tricornutum as model organism to study alkaline

24 flocculation of marine microalgae cultured in seawater medium. Flocculation started

25 when $\mathrm{pH}$ was increased to 10 and flocculation efficiency reached $90 \%$ when $\mathrm{pH}$ was

26 10.5, which was consistent with precipitation modeling for brucite or $\mathrm{Mg}(\mathrm{OH})_{2}$.

27 Compared to freshwater species, more magnesium is needed to achieve flocculation

$28(>7.5 \mathrm{mM})$. Zeta potential measurements suggest that brucite precipitation caused

29 flocculation by charge neutralization. When calcium concentration was $12.5 \mathrm{mM}$,

30 flocculation was also observed at a $\mathrm{pH}$ of 10 . Zeta potential remained negative up to

$31 \mathrm{pH}$ 11.5, suggesting that precipitated calcite caused flocculation by a sweeping

32 coagulation mechanism.

33

34 Keywords: coagulation, marine algae, enmeshment, biomass, autoflocculation,

\section{5 ballasted flocculation}


40 Microalgae are a promising new source of biomass for production of food, animal

41 feed, biofuels and feedstocks for the chemical industry (Draaisma et al., 2013; Foley

42 et al., 2011). Production of microalgal biomass is still very expensive and energy-

43 intensive and is therefore only economically feasible for high-value products such as

44 nutritional supplements or fine chemicals (Guedes et al., 2011). The high cost and

45 energy demand of microalgal biomass production is to a large extent due to the cost of 46 harvesting (Barros et al., 2015; Show et al., 2013).

48 Flocculation is seen as a promising way to reduce the cost and energy inputs of 49 harvesting of microalgae as it may allow a first separation of the biomass from the 50 culture medium by simple gravity sedimentation (Benemann et al., 1980; Molina 51 Grima et al., 2003; Schlesinger et al., 2012). In recent years, several methods for 52 flocculating microalgae have been developed, including chemical flocculation using 53 metal coagulants or cationic polymer flocculants, electro-coagulation-flocculation 54 using aluminum electrodes, microbial flocculation using bacteria or fungi and the use 55 of magnetic nanoparticles (Vandamme et al., 2013).

57 A simple and inexpensive way of inducing flocculation is by spontaneous flocculation 58 at high $\mathrm{pH}$, which is referred to as autoflocculation or alkaline flocculation (Sukenik 59 and Shelef, 1984). Studies in the 1980's demonstrated that autoflocculation was 60 related to precipitation of calcium phosphate (Lavoie and Noüe, 1987; Sukenik et al., 61 1985). Autoflocculation by calcium phosphate precipitation, however, only occurs 
when phosphate concentrations are high $(>0.35 \mathrm{mM})$, making this method only useful in phosphate-rich wastewaters (Beuckels et al., 2013).

64

When phosphate concentrations are low, autoflocculation can still be induced by precipitation of calcite (calcium carbonate) and/or brucite (magnesium hydroxide). In

lime and is known as lime softening (Ayoub et al., 1986; Elmaleh, 1996). In a previous study, we elucidated the relative contribution of calcium and magnesium precipitation to alkaline flocculation for the freshwater microalgae Chlorella vulgaris (Vandamme et al., 2012). Although both calcium and magnesium precipitated during alkaline flocculation, flocculation could be induced in media containing only magnesium but not in media containing only calcium. This suggested that, in freshwater media, alkaline flocculation is induced by precipitation of magnesium hydroxide or brucite but not by precipitation of calcite.

Autoflocculation has also been observed in seawater. In seawater, concentrations of calcium and magnesium are much higher than in freshwater. Therefore, the relative importance of calcite and brucite in inducing flocculation may be different. The fact that flocculation starts at a lower $\mathrm{pH}$ in seawater than in freshwater suggest that the underlying mechanism may indeed be different (Sales and Abreu, 2014; Spilling et al., 2011). Experiments with Dunaliella suggested that flocculation at high $\mathrm{pH}$ was mainly related to brucite precipitation (Besson and Guiraud, 2013). Because Dunaliella is grown in hypersaline media, the alkaline flocculation mechanism may be different in regular seawater media. 
87 The aim of this study was to understand the role of calcium and magnesium salts in

88 alkaline flocculation of microalgae in seawater media. Therefore, we combined

89 precipitation and surface speciation modeling with jar test flocculation experiments

90 for the model marine microalgae Phaeodactylum tricornutum. We elucidated the

91 relative importance of calcite and brucite by investigating flocculation as a function of

$92 \mathrm{pH}$ in artificial seawater medium containing only calcium, only magnesium or both

93 cations. Additionally, zeta potential measurements were conducted to study alkaline

94 flocculation in medium with variable concentrations of calcium and magnesium.

95

96 
Materials and methods

98

Precipitation model and surface speciation for brucite and calcite in seawater

100

The concentrations of magnesium (hydroxide) and calcium (carbonate) were

101

modelled as function of $\mathrm{pH}$ in seawater to understand the calcium and magnesium

102

speciation during alkaline flocculation. The concentrations of total dissolved

103

magnesium, total dissolved calcium, (bi)carbonate, calcite as $\mathrm{CaCO}_{3} \mathrm{xH}_{2} \mathrm{O}(\mathrm{s})$ and

104

brucite as $\mathrm{Mg}(\mathrm{OH})_{2}$ (active) were modelled as functions of $\mathrm{pH}$ using Visual Minteq

105

3.0 (KTH, Department of Sustainable Development, Environmental Science and

106 Engineering, Stockholm, Sweden). The nominal composition of synthetic seawater

107 medium (Table 1) was entered using a temperature of $25^{\circ} \mathrm{C}$.

108 The surface speciation of brucite and calcite was modeled through simple protonation

109 and deprotonation reactions described in Brady et al. (2014). Calculations were

110 carried out using the speciation code PHREEQC (Parkhurst and Appelo, 1999). The

111 surface site was assumed to be 10 sites $\mathrm{nm}^{-2}$ (Pokrovsky, 2004). The surface area was 112 set to $10^{4} \mathrm{~m}^{2} \mathrm{~mol}^{-1}$.

113

114 Culturing of microalgae

115

116 Phaeodactylum tricornutum (Pt 86, UGent Belgium) was cultivated in dechlorinated

117 deionized water to which $30 \mathrm{~g} \mathrm{~L}^{-1}$ synthetic sea salt (Homarsel, Zoutman, Belgium)

118 was added. This synthetic seawater (Table 1) was enriched with inorganic nutrients

119 according to the concentrations of the Wright's Cryptophyte medium (Guillard and

120 Lorenzen, 1972). Chlorella vulgaris was cultivated in freshwater medium (Table 1).

121 Both species were cultured in $30 \mathrm{~L}$ bubble column photobioreactors that were mixed 
122 by sparging with $0.2 \mu \mathrm{m}$-filtered air $\left(5 \mathrm{~L} \mathrm{~min}^{-1}\right)$. The $\mathrm{pH}$ was controlled at 8.5 by

123 addition of $\mathrm{CO}_{2}$-enriched air (2-3\%) using a pH-stat system. Growth of the

124 microalgae in the photobioreactor was monitored by measuring the absorbance at

$125750 \mathrm{~nm}$. Flocculation experiments were conducted at the end of the exponential

126 growth phase when microalgal density was approximately $0.4 \mathrm{~g} \mathrm{~L}^{-1}$ dry weight.

127

128

General setup of flocculation experiments

130 Alkaline flocculation was assessed using jar test experiments. $100 \mathrm{~mL}$ jars were

131 stirred using a magnetic stirrer and $\mathrm{pH}$ was adjusted between 9 and 12 by addition of

$1320.5 \mathrm{M}$ sodium hydroxide. The microalgal suspension was mixed intensively

133 (1000 rpm) for 10 min during and just after $\mathrm{pH}$ adjustment, followed by a gentle

134 mixing (250 rpm) for another $20 \mathrm{~min}$. The suspension was subsequently allowed to

135 settle for $30 \mathrm{~min}$. The flocculation efficiency was estimated by comparing absorbance

136 at $750 \mathrm{~nm}$ between the $\mathrm{pH}$-adjusted treatment and a control treatment. Samples for

137 analysis of optical density were collected in the middle of the clarified zone. The

138 flocculation efficiency $\eta_{a}$ was calculated as:

139

$\eta_{a}=\frac{O D_{i}-O D_{f}}{O D_{i}}($ Eq. 1)

140 where $\mathrm{OD}_{\mathrm{i}}$ is the optical density of the control suspension after 30 min sedimentation

141 without $\mathrm{pH}$ adjustment, and $\mathrm{OD}_{\mathrm{f}}$ is the optical density of the suspension after $\mathrm{pH}$

142 adjustment. Each test was carried out in duplicate.

144 The role of magnesium and calcium in flocculation 
146 The relative importance of calcium and magnesium in alkaline flocculation was

147 investigated by testing whether alkaline flocculation could be induced in media with

148 varying concentrations of calcium or magnesium. Phaeodactylum was separated from

149 the medium using centrifugation at 4,000 $\mathrm{g}$ and resuspended in fresh prepared

150 synthetic seawater medium lacking calcium chloride and magnesium sulphate.

151 Preliminary tests had shown that Phaeodactylum formed a stable suspension after

152 resuspension in its original medium and that centrifugation and resuspension had no

153 effect on alkaline flocculation. To investigate the role of calcium chloride in alkaline

154 flocculation, $\mathrm{CaCl}_{2} \cdot 2 \mathrm{H}_{2} \mathrm{O}$ was added in a concentration between 0 and $12.5 \mathrm{mM}$. To

155 investigate the role of magnesium, magnesium sulphate $\left(\mathrm{MgSO}_{4} .7 \mathrm{H}_{2} \mathrm{O}\right)$ was added in

156 concentration between 0 and $80 \mathrm{mM}$. The maximum concentrations used are in the

157 order of magnitude of the concentrations of these cations occurring in seawater. The

158 flocculation efficiency of Phaeodactylum cells in these synthetic media was assessed

159 at three $\mathrm{pH}$ levels $(9.5 ; 10 ; 10.5)$ using jar tests as described above.

160

161 To evaluate whether magnesium or calcium had precipitated during flocculation, the 162 concentrations of magnesium and calcium were analyzed after flocculation in the 163 supernatant and in the biomass pellet using ICP-MS (Agilent 7700x ICP-MS) based 164 on a method previously used in (Vandamme et al., 2015). In short, supernatant and 165 biomass pellet were separated using centrifugation at $3,005 \mathrm{~g}$ and both fractions were 166 stored at $-20{ }^{\circ} \mathrm{C}$. Prior to analysis, samples from the supernatant were diluted and 167 acidified using nitric acid (70\%) to a final concentration of $0.1 \mathrm{M}$. The samples from 168 the biomass pellet were acidified with $10 \mathrm{ml}$ concentrated HNO3 (70 \%) and after 48 $169 \mathrm{~h}$ the clear solution was diluted 20 times with deionized water. 
171 Because precipitation of calcite is relatively slow compared to precipitation of

172 magnesium hydroxide, the influence of additional mixing time was tested for

173 Phaeodactylum resupended as previously described in synthetic seawater medium

174 containing $5 \mathrm{mM}$ of bicarbonate and lacking sulfates and magnesium. Jar tests were

175 conducted as previously described and mixing time was varied from 35 till 95 min in

176 triplicate. Flocculation efficiency was determined as previous described.

177

\section{Zeta potential measurements}

180 The surface charge Phaeodactylum cells was assessed by the zeta potential based on

181 electrophoretic mobility using a Malvern Zetasizer Nano. Zeta potential was

182 calculated using the Smoluchowski equation. Zeta potential was measured at different

$183 \mathrm{pH}$ levels in media containing either calcium bicarbonate or magnesium sulphate at

184 concentrations of $7.5 \mathrm{mM}$. The $\mathrm{pH}$ was increased stepwise from 8 to 11.5 using

185 sodium hydroxide $(0.5 \mathrm{M})$. The zeta potential was evaluated at room temperature in

186 the electrophoresis cell. For each data point, triplicate cultures were taken for

187 measurements and for each data, approximately, 25 readings were done. The average

188 values were then reported. 
189

190

191

192

193 Precipitation of magnesium as brucite (magnesium hydroxide) is predicted to start

194 when $\mathrm{pH}$ exceeds 10 . At $\mathrm{pH} 10.5$, residual concentration of $\mathrm{Mg}^{2+}$ in the seawater is

195 below $40 \mathrm{mM}$ (Fig 1A). As brucite precipitation is quadratic in $\mathrm{OH}^{-}$, most of the

196 available $\mathrm{Mg}^{2+}$ is predicted to be precipitated as brucite at $\mathrm{pH} \geq 11$. The surface

197 charge of brucite crystals is determined by the $\mathrm{pH}$ of the medium. As the isoelectric

198 point of brucite is 11 , the surface charge of brucite precipitates is positive up to a $\mathrm{pH}$

199 of 11 (Fig 1C). As a result, brucite precipitation should be capable of causing

200 coagulation of microalgae through charge neutralisation in the $\mathrm{pH}$ range 10 to 11.

201

202 Precipitation of calcium as calcite (calcium carbonate) is predicted to start when $\mathrm{pH}$

203 exceeds $8.5 . \mathrm{Ca}^{2+}$ concentration in seawater is approximately 9 to $12 \mathrm{mM}$ while

204 carbonate concentration is variable but rarely exceeds $5 \mathrm{mM}$ in seawaters (Feely et al.,

205 2004). Therefore, calcite precipitation in seawater is limited by carbonate availability.

206 As a result, only a fraction of the calcium present in seawater will precipitate as

207 calcite. Calcite precipitation increases with increasing $\mathrm{pH}$ and reaches a maximum at

$208 \mathrm{pH} 11$ (Fig 1B). Over this $\mathrm{pH}$ range, the concentration of carbonate increases as a

209 result of conversion of bicarbonate to carbonate by increasing $\mathrm{pH}\left(\mathrm{pK}_{\mathrm{a} 2}=8.95\right.$ in

210 seawater $25^{\circ} \mathrm{C}$ ). The surface charge of calcite precipitates is determined by adsorption

211 of calcium, magnesium, carbonate and sulphates on the surface of calcite crystals

212 (Brady et al., 2014). The calcite surface in seawater is dominated by sorbed $\mathrm{Mg}$,

$213>\mathrm{CO}_{3} \mathrm{Mg}^{+}$, below $\mathrm{pH} 11$, and $>\mathrm{CO}_{3}{ }^{-}$groups at $\mathrm{pH}>11($ Fig 1D). When seawater 
concentrations of calcium and magnesium are present, the overall surface charge is

predicted to be positive at $\mathrm{pH}<11$.

Flocculation of Phaeodactylum tricornutum in synthetic seawater medium as a

function of pH, magnesium and calcium concentrations.

When alkaline flocculation was induced in synthetic seawater containing both

221 calcium and magnesium, flocculation started as soon as $\mathrm{pH}$ was 10 and reached over 90\% when $\mathrm{pH}$ was 10.5 (Fig 2). This was at a lower $\mathrm{pH}$ than in freshwater, where flocculation occurred at a pH of 11 (Vandamme et al., 2012). Similar results have

224 been reported in recent studies in experiments with the marine microalgae 225 Nannochloropsis, where flocculation was initiated at a $\mathrm{pH}$ of 10 to 10.5 (Sales and 226 Abreu, 2014; Şirin et al., 2013). At a pH of 10.5, the total dissolved magnesium 227 concentration remaining in the medium was $70 \mathrm{mM}$ and the total dissolved calcium 228 concentration was $8.5 \mathrm{mM}$, which indicates that only $10.5 \mathrm{mM}$ magnesium and 0.6 $229 \mathrm{mM}$ calcium had precipitated during flocculation. The amount of precipitation of both 230 magnesium and calcium is significantly less than the equilibrium expected (cf. Fig 1).

231 In general, brucite precipitation is expected to be relatively rapid so that the fact that 232 equilibrium levels are not reached will motivated further investigation of the effects 233 of mixing time below (cf. Fig. 5).

235 We then evaluated whether alkaline flocculation could be induced in synthetic 236 seawater lacking either calcium, or magnesium or both (Fig 3). In these experiments, 237 we also monitored zeta potential to evaluate whether flocculation might be associated 238 with changes in the surface charge of microalgal cells. No flocculation occurred at 
239 any of the $\mathrm{pH}$ levels tested when both calcium and magnesium were lacking in the

240 medium. Also, zeta potential remained constant when $\mathrm{pH}$ was increased (Fig 4A).

242 In medium lacking calcium, flocculation could be induced when magnesium was

243 added to the medium. Flocculation efficiencies higher than $80 \%$ were observed at the

244 same $\mathrm{pH}$ as in the medium containing both calcium and magnesium ( $\mathrm{pH}$ 10.5; Fig

$2453 \mathrm{~A})$. When magnesium concentration in the medium was $0.15 \mathrm{mM}$ or higher,

246 moderate flocculation occurred at pH 10.5 (flocculation efficiency of about $40 \%$ ).

247 When magnesium concentration was $7.5 \mathrm{mM}$ or higher, the flocculation efficiency

248 increased to about $90 \%$ at $\mathrm{pH} 10.5$. In medium with $7.5 \mathrm{mM}$ magnesium, the zeta

249 potential increased from negative to positive values when $\mathrm{pH}$ was increased above $\mathrm{pH}$

25010.5 (Fig 4B). As predicted by precipitation and surface complexation modeling, our

251 experimental observations confirm that alkaline flocculation can be induced in

252 medium containing only magnesium, and that flocculation is at least partly mediated

253 by charge neutralization. In a previous study, we demonstrated that magnesium

254 hydroxide precipitation can cause flocculation of the freshwater microalgae Chlorella

255 vulgaris (Vandamme et al., 2012). For Chlorella, however, a lower magnesium

256 concentration was required to induce alkaline flocculation than for Phaeodactylum. It

257 is unlikely that this difference is due to differences in biomass concentrations, as

258 biomass concentrations were comparable for both species $\left(0.4 \mathrm{mg} \mathrm{L}^{-1}\right.$ in Chlorella

259 versus $0.3 \mathrm{mg} \mathrm{L}^{-1}$ in Phaeodactylum). The observed difference may be due to

260 differences in cell properties between Chlorella and Phaeodactylum and/or due to an

261 effect of the ionic strength of the medium (freshwater versus seawater) (Ayoub et al., 262 1986). 
264 In medium lacking magnesium, flocculation occurred when calcium was added to the 265 medium. When calcium concentration was 2.5 and $5 \mathrm{mM}$, flocculation only occurred

266 at $\mathrm{pH} 10.5$ (Fig 3B). When calcium concentration was $12.5 \mathrm{mM}$ (the normal

267 concentration in seawater medium) flocculation was also observed at a $\mathrm{pH}$ of 10 , but

268 the flocculation efficiency was lower than when $\mathrm{pH}$ was 10.5. This is in agreement

269 with the $50 \%$ flocculation efficiency observed at $\mathrm{pH} 10$ when calcium is present in

270 sufficient concentration in artificial seawater medium (Fig 2). In medium containing

$2717.5 \mathrm{mM}$ calcium, the zeta potential remained negative up to $\mathrm{pH} 11.5$ (Fig 4C).

272 Calculations using the results of Brady et al. (2014) as in Fig. 1 suggest that in the

273 absence of magnesium, the calcite surface remains negative, although the magnitude

274 of the negative charge varies significantly with the $\mathrm{Ca}^{+} / \mathrm{CO}_{3}^{-2}$ ratio. For the solutions

275 studied here where calcium concentrations go from 1.25 to 12.5 the reduction in the

276 calcite surface charge is reduced by more than an order of magnitude, making

277 interaction between precipitated calcite and the anionic algal surface more favorable.

278 Our experimental results showed that alkaline flocculation can also be induced in

279 water containing calcium but lacking magnesium. Flocculation must have been due to

280 calcite precipitation and not calcium phosphate precipitation as phosphate

281 concentrations in the medium were very low $(<0.05 \mathrm{mM})$. While our model predicted

282 that calcite precipitation is initiated at $\mathrm{pH} 8.5$, our experiments showed that

283 flocculation only occurred at a $\mathrm{pH}$ of 10 , or an even higher $\mathrm{pH}$ when calcium

284 concentrations were lower than those typically occurring in seawater. This

285 discrepancy could be related to kinetic aspects of calcite formation, which is not

286 included in our model (Shaojun and Mucci, 1993). Therefore we additionally tested

287 the influence of mixing time on flocculation efficiency as a function of $\mathrm{pH}$ in

288 synthetic seawater containing $5 \mathrm{mM}$ of bicarbonate and lacking magnesium and 
289 sulfates (Fig 5). At pH 8, no flocculation was observed even for 95 min of mixing. At

$290 \mathrm{pH} 9$, flocculation efficiency was $34 \%$ for 35 min of mixing and increased up to $70 \%$

291 for $50 \mathrm{~min}$ of mixing. This increase in flocculation efficiency at $\mathrm{pH} 9$ is now in

292 correspondence with the predictions for calcite precipitations (Fig 1B). This

293 additional experiment showed that in contrast to brucite, calcite mediated flocculation

294 requires longer mixing than 30 minutes, which is traditionally used in jar tests

295 (Bratby, 2006).

\section{Relative importance of calcite and brucite}

299 When $\mathrm{pH}$ of Phaeodactylum cultures in synthetic seawater medium is increased,

300 alkaline flocculation occured at a pH of $10-10.5$ (Fig 2). In this $\mathrm{pH}$ window,

301 precipitation of both calcite and brucite may contribute to flocculation. Theoretically,

302 calcite could precipitate at a lower $\mathrm{pH}$ of 8.5 but it was demonstrated that longer

303 mixing was needed to obtain satisfactory flocculation in relation to precipitation

304 model (Fig 5). In outdoor microalgal cultures, $\mathrm{pH}$ increases gradually due to

305 photosynthetic activity and $\mathrm{pH}$ variation is stabilized by supply of carbon dioxide.

306 Due to exchange with the atmosphere and conversion of carbon dioxide to carbonates,

307 calcite concentrations may slowly increase and induce flocculation. Measurements of

308 zeta potential indicated that alkaline flocculation of Phaeodactylum in medium

309 lacking magnesium was not associated with a reversal of the surface charge (Fig 4C).

310 This suggests that calcite precipitates were either uncharged or negatively charged

311 and flocculation occurred through a sweeping mechanism rather than charge

312 neutralization. The surface charge of calcite crystals, however, depends on the

313 presence of both calcium and magnesium in solution (Brady et al. 2014). The medium 
314 that was used in our experiment for Figs. 4C and 5 lacked magnesium, and in the

315 absence of magnesium the calcite surface charge is expected to be negative; similar

316 behavior is seen in Fig. 1D for $\mathrm{pH}$ values where magnesium precipitates as brucite.

317 As discussed around Fig. 1D, the calcite surface charge is a balance between sorption

318 of cations as $>\mathrm{CO}_{3} \mathrm{Ca}^{+}$and $>\mathrm{CO}_{3} \mathrm{Mg}^{+}$versus $>\mathrm{CO}_{3}{ }^{-}$surface groups, and the lack of

$319 \mathrm{Mg}$ shifts the balance to negative.

320

321 According to our experiments, flocculation by precipitation of brucite occurred in a

322 very narrow $\mathrm{pH}$ interval of 10 to 10.5 . This is a consequence of the strong

323 dependence of brucite precipitation on $\mathrm{OH}^{-}$as well as the relatively rapid kinetics

324 associated with brucite precipitation. As a $\mathrm{pH}$ of 10.5 is near the limit of the process

325 of bicarbonate utilization in photosynthesis (Prins and Elzenga, 1989), addition of

326 base may be required to induce flocculation by brucite precipitation; however, this

327 might be mitigated by the buffering associated with brucite precipitation. The

328 magnesium hydroxide that is formed is positively charged and will cause immediate

329 flocculation through charge neutralization and possibly also through a sweeping

330 mechanism. Although the high ionic strength of seawater results in higher magnesium

331 requirements to induce flocculation when compared to freshwater, this is not a

332 limiting factor due to the high magnesium concentration in seawater. This makes

333 brucite mediated flocculation an easier process to control compared to calcite

334 mediated flocculation.

336 Ayoub et al. 1986 concluded that seawater induced microalgal flocculation was

337 independent of microalgal biomass concentration, while in freshwater conditions

338 there was a linear behavior reported between magnesium and biomass concentration 
339

for alkaline flocculation associated with brucite precipitation (García-Pérez et al.,

340

2014). However, present results in marine conditions showed that brucite-mediated

341 flocculation was mainly caused by charge neutralization. By this, one could expect a

342 linear behavior of $\mathrm{Mg}$ dosage with biomass concentration which is in line with the

343 observation made by García-Pérez et al. (2014). While for calcite, one could expect a

344 independent behavior between calcium dosage and biomass concentration because

345 calcite-mediated flocculation was mainly caused by sweeping, which is in line with

346 the conclusions made by Ayoub et al. 1986. This suggests that flocculation conditions

347 and process strategy could be adapted based on the initial biomass concentration. The

348 effect of microalgae biomass concentration on the flocculation efficiency, $\mathrm{pH}$,

349 calcium and magnesium concentration in marine conditions disserves therefore

350 further detailed study.

351

352 Conclusions

353

354 This study demonstrates that alkaline flocculation can be induced in a narrow $\mathrm{pH}$

355 range of 10-10.5 for the marine diatom Phaeodactylum tricornutum by the

356 precipitation of brucite. A higher dosage of magnesium was needed to obtain similar

357 flocculation efficiency compared to freshwater conditions. Alkaline flocculation was

358 also induced in medium lacking magnesium. The precipitation of calcite was slower

359 compared to brucite but it caused alkaline flocculation as well. This process was

360 based on a sweeping mechanism, while brucite mainly caused alkaline flocculation

361 based on a charge neutralization mechanism.

362

\section{Acknowledgements}


365 The research presented in this paper was financially supported by the Research

366 Foundation Flanders Belgium (FWO Postdoctoral Fellowship D. Vandamme, FWO

367 Ph.D. fellowship A. Beuckels). We thank Sina Salim, Prof. Marjan Vermuë and Prof.

368 Rene Wijffels, Bio-process Engineering, WUR, Wageningen for the usage of the

369 Malvern Zetasizer during our experiments. We thank Kristin Coorevits and Prof. Erik

370 Smolders, Division of Soil and Water Management, KU Leuven for the ICP-MS

371 analysis. We thank Saul García-Pérez and Manel Azzabi for their contribution to this

372 work. This work at Sandia National Laboratories was partially supported by the

373 Laboratory Directed Research and Development program and was partially supported

374 by the BioEnergy Technology Office, U.S. Department of Energy under Award

375 9.1.1.3_DE-EE0005995. Sandia National Laboratories is a multi-program laboratory

376 managed and operated by Sandia Corporation, a wholly owned subsidiary of

377 Lockheed Martin Corporation, for the U.S. Department of Energy's National Nuclear

378 Security Administration under contract DE-AC04-94AL85000.

379 


\section{References}

Ayoub, G.M., Lee, S.I., Koopman, B., 1986. Seawater induced algal flocculation. Water Res. 20, 1265-1271.

Barros, A.I., Gonçalves, A.L., Simões, M., Pires, J.C.M., 2015. Harvesting techniques applied to microalgae: A review. Renew. Sustain. Energy Rev. 41, 1489-1500.

Benemann, J.R., Koopman, B., Eisenberg, D., Goebel, R., 1980. Development of microalgal harvesting and high-rate pond technologies in California, in: Shelef, G., Soeder, C. (Eds.), Algae Biomass. Elsevier, pp. 457-94.

Besson, A., Guiraud, P., 2013. High-pH-induced flocculation-flotation of the hypersaline microalga Dunaliella salina. Bioresour. Technol. 147C, 464-470.

Beuckels, A., Depraetere, O., Vandamme, D., Foubert, I., Smolders, E., Muylaert, K., 2013. Influence of organic matter on flocculation of Chlorella vulgaris by calcium phosphate precipitation. Biomass and Bioenergy 54, 107-114.

Brady, P. V, Pohl, P.I., Hewson, J.C., 2014 . A coordination chemistry model of algal autoflocculation. Algal Res. 5, 226-230.

Bratby, J., 2006. Coagulation and flocculation in water and wastewater treatment. IWA Publishing, London, UK.

Draaisma, R.B., Wijffels, R.H., Slegers, P.M.E., Brentner, L.B., Roy, A., Barbosa, M.J., 2013. Food commodities from microalgae. Curr. Opin. Biotechnol. 24, 169-77.

Elmaleh, S., 1996. Suspended solids abatement by $\mathrm{pH}$ increase-upgrading of an oxidation pond effluent. Water Res. 30, 2357-2362.

Feely, R.A., Sabine, C.L., Lee, K., Berelson, W., Kleypas, J., Fabry, V.J., Millero, F.J., 2004. Impact of anthropogenic $\mathrm{CO} 2$ on the CaCO3 system in the oceans. Science 305, 362-6.

Foley, P.M., Beach, E.S., Zimmerman, J.B., 2011. Algae as a source of renewable chemicals: opportunities and challenges. Green Chem. 13, 1399.

García-Pérez, J.S., Beuckels, A., Vandamme, D., Depraetere, O., Foubert, I., Parra, R., Muylaert, K., 2014. Influence of magnesium concentration, biomass concentration and $\mathrm{pH}$ on flocculation of Chlorella vulgaris. Algal Res. 3, 24-29.

Guedes, C., Amaro, H.M., Malcata, F.X., 2011. Microalgae as sources of high addedvalue compounds--a brief review of recent work. Biotechnol. Prog. 27, 597-613.

Guillard, R.R.L., Lorenzen, C.L., 1972. Yellow-green algae with chlorophyllide c. J. Phycol. 8, 1-14. 
Lavoie, A., Noüe, J., 1987. Harvesting of scenedesmus obliquus in wastewaters: Auto- or bioflocculation? Biotechnol. Bioeng. 30, 852-859.

Molina Grima, E., Belarbi, E.H., Acién Fernández, F.G., Robles Medina, A., Chisti, Y., 2003. Recovery of microalgal biomass and metabolites: process options and economics. Biotechnol. Adv. 20, 491-515.

Parkhurst, D.L., Appelo, A.J., 1999. User's guide to PHREEQC (Version 2): A computer program for speciation, batch-reaction, one-dimensional transport, and inverse geochemical calculations.

Pokrovsky, O., 2004. Experimental study of brucite dissolution and precipitation in aqueous solutions: surface speciation and chemical affinity control. Geochim. Cosmochim. Acta 68, 31-45.

Prins, H.B. a., Elzenga, J.T.M., 1989. Bicarbonate utilization: Function and mechanism. Aquat. Bot. 34, 59-83.

Sales, R., Abreu, P.C., 2014. Use of Natural pH Variation to Increase the Flocculation of the Marine Microalgae Nannochloropsis oculata. Appl. Biochem. Biotechnol.

Schlesinger, A., Eisenstadt, D., Bar-Gil, A., Carmely, H., Einbinder, S., Gressel, J., 2012. Inexpensive non-toxic flocculation of microalgae contradicts theories; overcoming a major hurdle to bulk algal production. Biotechnol. Adv. 30, 102330 .

Shaojun, Z., Mucci, A., 1993. Calcite precipitation in seawater using a constant addition technique: A new overall reaction kinetic expression. Geochim. Cosmochim. Acta 57, 1409-1417.

Show, K.-Y., Lee, D.-J., Chang, J.-S., 2013. Algal biomass dehydration. Bioresour. Technol. 135, 720-9.

Şirin, S., Clavero, E., Salvadó, J., 2013. Potential pre-concentration methods for Nannochloropsis gaditana and a comparative study of pre-concentrated sample properties. Bioresour. Technol. 132, 293-304.

Spilling, K., Seppälä, J., Tamminen, T., 2011. Inducing autoflocculation in the diatom Phaeodactylum tricornutum through CO2 regulation. J. Appl. Phycol. 23, 959966.

Sukenik, A., Schröder, W., Lauer, J., Shelef, G., Soeder, C., 1985. Coprecipitation of microalgal biomass with calcium and phosphate ions. Water Res. 19, 127-129.

Sukenik, A., Shelef, G., 1984. Algal autoflocculation-verification and proposed mechanism. Biotechnol. Bioeng. 26, 142-147.

Vandamme, D., Beuckels, A., Markou, G., Foubert, I., Muylaert, K., 2015. Reversible Flocculation of Microalgae using Magnesium Hydroxide. BioEnergy Res. 8, $716-725$. 
Vandamme, D., Foubert, I., Fraeye, I., Meesschaert, B., Muylaert, K., 2012. Flocculation of Chlorella vulgaris induced by high $\mathrm{pH}$ : role of magnesium and calcium and practical implications. Bioresour. Technol. 105, 114-119.

455

Vandamme, D., Foubert, I., Muylaert, K., 2013. Flocculation as a low-cost method for 456 harvesting microalgae for bulk biomass production. Trends Biotechnol. 31, 233458

459 
460

461

462

463

464

465

466

467

468

469

470

471

472

473

474

475

476

477

478

479

480

481

482

483

484

Figure Captions

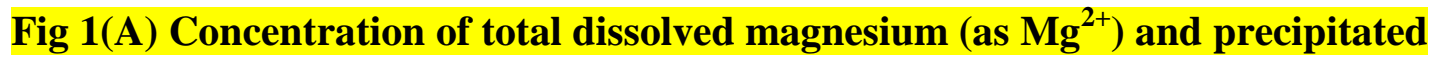
brucite (as $\mathrm{Mg}(\mathrm{OH})_{2}$ (active); (B) total dissolved calcium (as $\mathrm{Ca}^{2+}$ ), bicarbonate $\left(\right.$ as $\left.\mathrm{HCO}_{3}{ }^{-}\right)$carbonate (as $\mathrm{CO}_{3}{ }^{2-}$ ) and precipitated calcite (as $\mathrm{CaCO}_{3} \times \mathrm{H}_{2} \mathrm{O}$ (s) modelled as function of pH in artificial seawater. (C) Brucite and (D) calcite surface speciation modelled as function of $\mathrm{pH}$ in artificial seawater.

Fig 2 Flocculation efficiency of Phaeodactylum tricornutum in synthetic media as function of $\mathrm{pH}(\mathrm{n}=2,1 \sigma)$

Fig 3 Flocculation efficiency of Phaeodactylum tricornutum cells resuspended in (A) synthetic seawater lacking calcium with varying concentrations of magnesium and (B) lacking magnesium with varying concentrations of calcium at pH levels 9.5, 10 and $10.5(n=2,1 \sigma)$

Fig 4 Zeta potential as function of $\mathrm{pH}$ for resuspended Phaeodactylum tricornutum (A) lacking calcium and magnesium, (B) with $7.5 \mathrm{mM}$ magnesium sulphate and (C) with $7.5 \mathrm{mM}$ calcium bicarbonate $(\mathrm{n}=3,1 \sigma)$

Fig 5 Influence of mixing time on flocculation efficiency for Phaeodactylum resuspended in synthetic seawater containing $5 \mathrm{mM}$ of bicarbonate lacking magnesium and sulphates at $\mathrm{pH} 8,9,10$ and $11(\mathrm{n}=2,1 \sigma)$ 
Table 1. Concentrations of the main ions in the medium used to culture Phaeodactylum tricornutum (synthetic seawater) in comparison with Wright's Cryptophyte freshwater medium used for Chlorella vulgaris

\begin{tabular}{ccc}
\hline & $\begin{array}{c}\text { Synthetic } \\
\text { seawater } \\
(\mathrm{mM})\end{array}$ & $\begin{array}{c}\text { Freshwater } \\
(\mathrm{mM})\end{array}$ \\
\hline $\mathrm{Cl}^{-}$ & 442.1 & 1.7 \\
$\mathrm{Na}^{+}$ & 338.6 & 1.9 \\
$\mathrm{Mg}^{2+}$ & 80.5 & 1.0 \\
$\mathrm{Ca}^{2+}$ & 9.1 & 2.7 \\
$\mathrm{~K}^{+}$ & 6.4 & 0.3 \\
$\mathrm{HCO}_{3}^{-}$ & 5.0 & 0.15 \\
$\mathrm{SO}_{4}{ }^{-}$ & 40.2 & 1.3 \\
\hline Conductivity $\left(\mathrm{mS} \mathrm{cm}^{-1}\right)$ & 43.0 & 0.8 \\
\hline
\end{tabular}



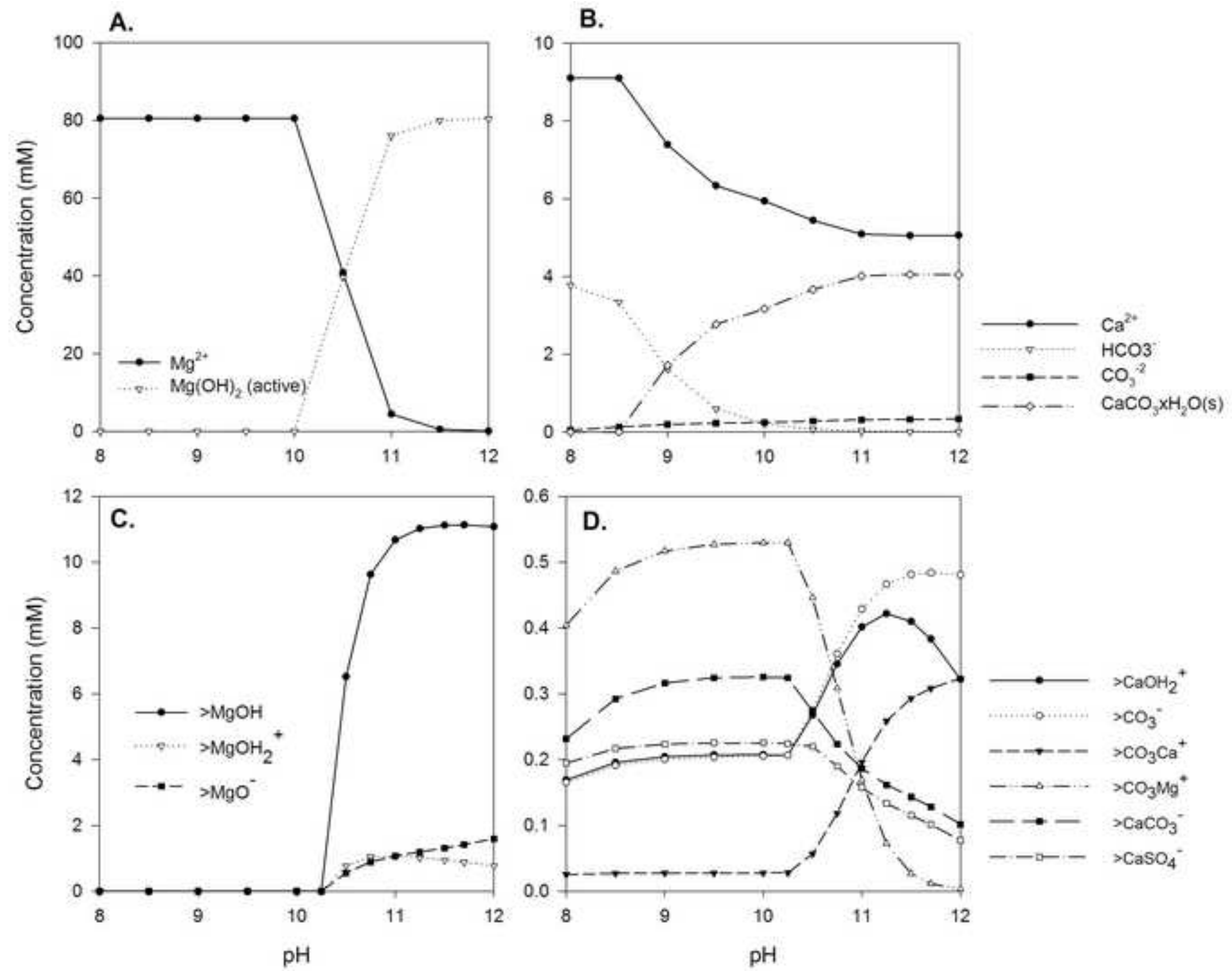


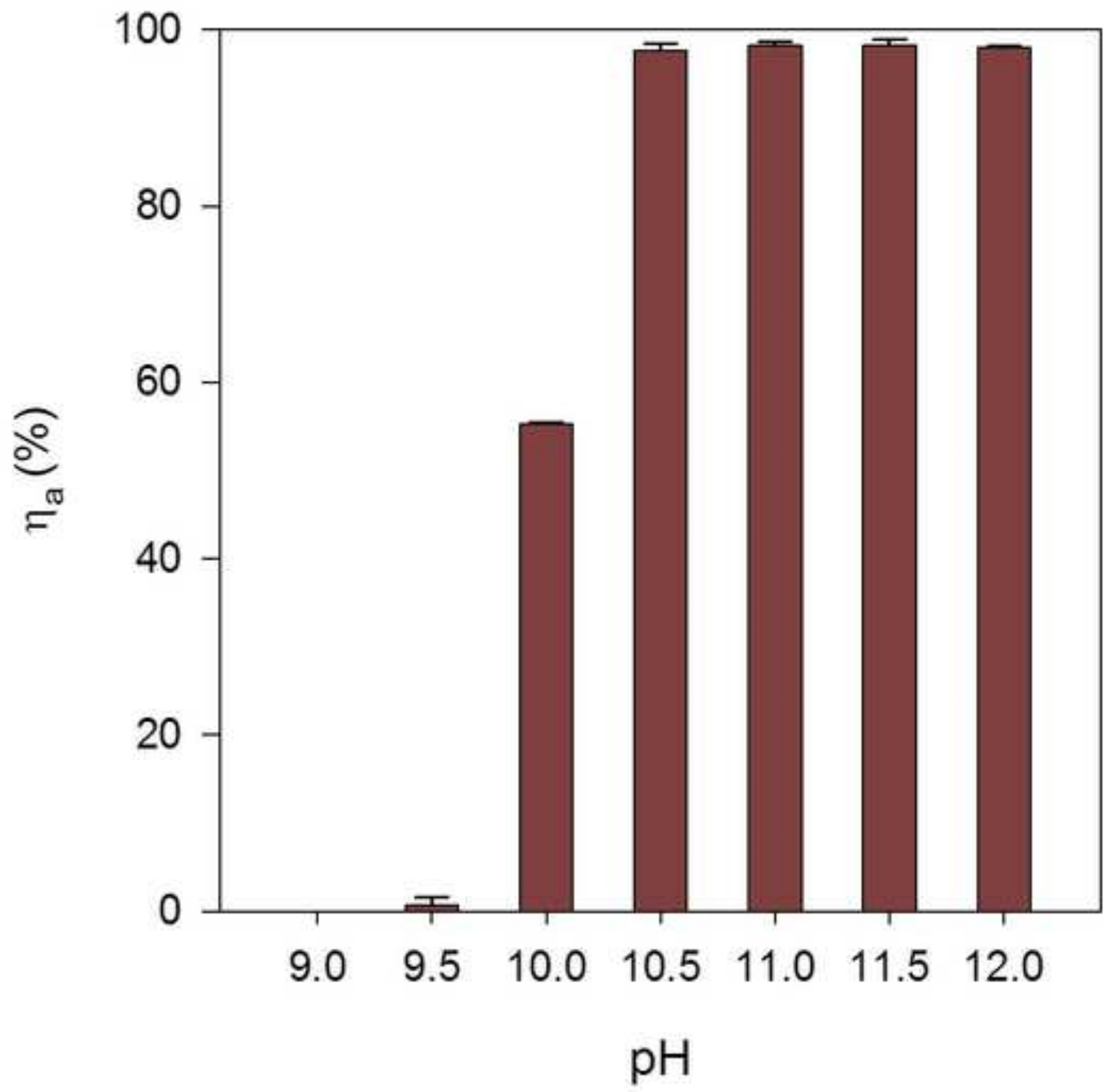




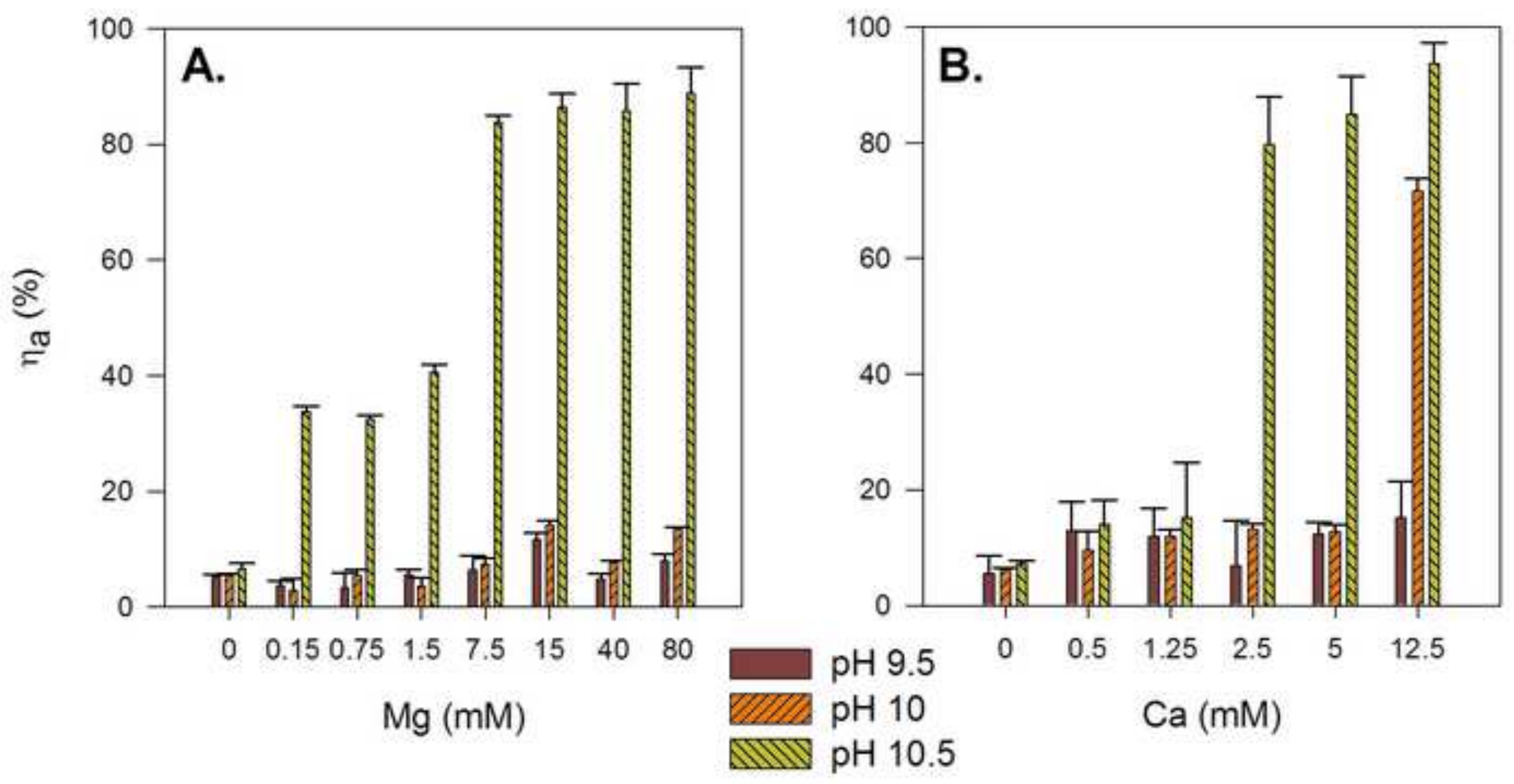



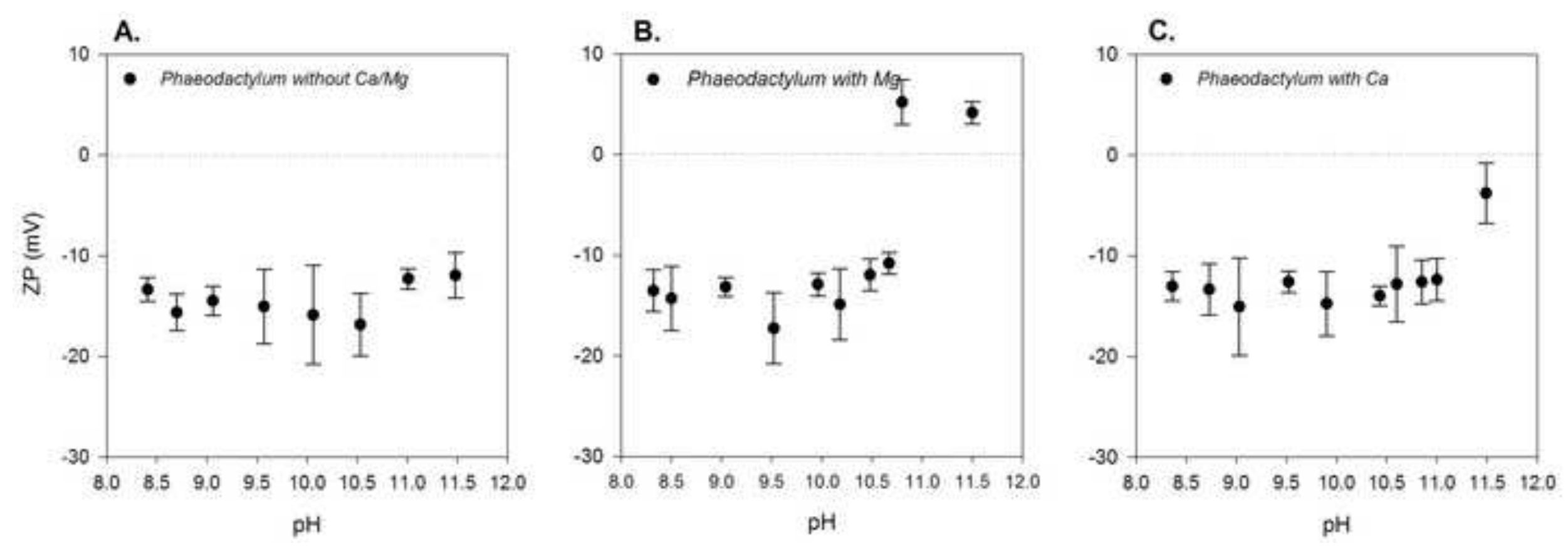


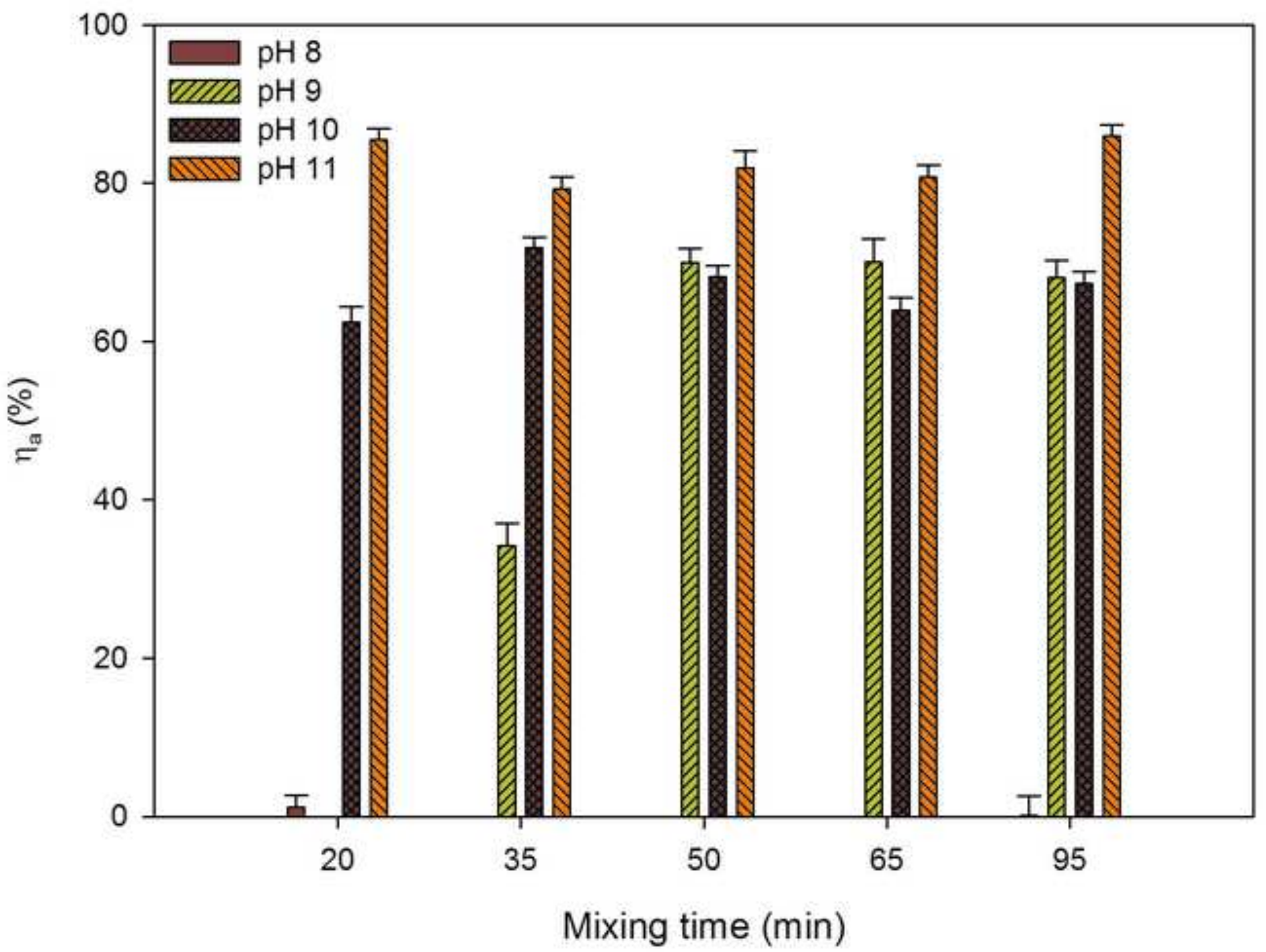

